\title{
Immunoprotection in goats against Haemonchus contortus after immunization with cysteine protease enriched protein fractions
}

\author{
Antonio RUIZ*, José Manuel Molina, Jorge Francisco GonZÁLEZ, \\ Magnolia María CONDE, Sergio MARTín, Yeray Isidro HERNÁNDEZ \\ Department of Animal Pathology (Parasitology and Parasitic Diseases), Faculty of Veterinary Medicine, \\ University of Las Palmas de Gran Canaria, Trasmontaña s/n, 35416 Arucas, Las Palmas, Spain
}

(Received 16 October 2003; accepted 22 March 2004)

\begin{abstract}
Haemonchus cysteine proteases, because of their apparent critical function in worm physiology, are considered important candidates in the immunological control of haemonchosis in sheep. Only limited information is, however, available on the immunoprotective properties of these molecules in goats. In the present study cysteine proteases of Haemonchus contortus adult worms isolated from a goat strain (Gran Canaria, Spain) were enriched by affinity chromatography and evaluated as immunoprotective antigens against caprine haemonchosis. The eggs per gram of faeces averaged over the whole experiment for unvaccinated goats $(550 \pm 13.5)$ was significantly greater $(P<0.001)$ than that of vaccinated goats $(61 \pm 2.9)$. Accordingly, the worm burden was significantly different between the groups $(P<0.05)$, with mean values of $247.5 \pm 43.8$ and $762.5 \pm 78.3$ worms per animal in the immunized and nonimmunized goats, respectively. The percentage of egg (89\%) and worm (68\%) reduction approached those attained with other immunogens used in sheep.
\end{abstract}

Haemonchus contortus / cysteine proteases / immunoprotection / goats

\section{INTRODUCTION}

Haemonchus contortus is a gastrointestinal nematode of small ruminants that causes anemia, emaciation, edema and gastric disturbance resulting principally from the loss of blood; heavy infection may be fatal. The control of $H$. contortus is largely based on pasture management and the use of anthelmintics. Clean pastures are not, however, readily available under intensive grazing conditions and there is an increasing occurrence of parasites resistant to anthelmintics $[4,11,15$, $28,30,31]$. Therefore, increasing attention has been given to the development of alternative control methods such as the use of vaccines.

Several studies have been carried out on the immunological control of haemonchosis. The immunoprophylactic properties of excretory-secretory products [23], different adult membrane antigens, such as H11 [17], H-gal-GP [26] or p26/23 [7] and antigens purified from larvae, such as the Hc-SL3 antigen [9] have been investigated. Cysteine proteases, because of their apparent critical function in worm nutrition, immune evasion or both [21] have also been assessed as

\footnotetext{
* Corresponding author: aruiz@dpat.ulpgc.es
} 
vaccine candidates. Cysteine proteases have been implicated in the protection conferred by vaccination with affinity purified detergent-soluble extracts of $H$. contortus $[1,14]$.

Most of the vaccination trials against $H$. contortus have been performed in sheep and relatively little is known about the immunological response of goats against these compounds, even though it is well documented that these host species show different susceptibilities to parasite infection $[8,18]$. In the present study, cysteine protease enriched protein fractions of $H$. contortus adult worms isolated from naturally infected goats were evaluated as immunoprotective antigens against caprine haemonchosis.

\section{MATERIALS AND METHODS}

\subsection{Parasites and antigens}

Parasites were obtained from a strain of $H$. contortus isolated from naturally infected goats in Gran Canaria (Spain). Adult worms were homogenized in $1 \mathrm{XPBS}$, centrifuged at $10000 \mathrm{~g}$ at $4{ }^{\circ} \mathrm{C}$ and the supernatant was collected, filtered $(0.22 \mu \mathrm{m})$ and stored at $-20{ }^{\circ} \mathrm{C}$ for subsequent analyses. Protein concentrations of the homogenates (PBS soluble protein extracts) were estimated by spectrophotometric assays at $595 \mathrm{~nm}$ with Bradford's Method [3].

\subsection{Proteolytic activity of Haemonchus PBS soluble protein extracts}

Proteolytic activity was determined in duplicate by colorimetric analysis using azocasein $(5 \mathrm{mg} / \mathrm{mL}), 2 \mathrm{mM}$ DTT and $50 \mu \mathrm{L}$ aliquots of homogenate $(2.5 \mathrm{mg} / \mathrm{mL})$ in a $0.5 \mathrm{~mL}$ assay volume. The samples were incubated at $37{ }^{\circ} \mathrm{C}$ overnight using $0.1 \mathrm{M}$ Phosphate ( $\mathrm{pH} 4,5$ and 6) or $0.1 \mathrm{M}$ Tris- $\mathrm{HCl}$ (pH 7, 8 and 9) as incubation buffers and unhydrolyzed substrate was precipitated on ice with $500 \mu \mathrm{L}$ trichloroacetic acid. After centrifugation $\left(10000 \mathrm{~g}\right.$ at $\left.4{ }^{\circ} \mathrm{C}\right)$, the absorb- ance of the supernatants was measured at $405 \mathrm{~nm}$. To characterize the protease activity, the protease inhibitors E64 $(0.2 \mathrm{mM})$, Pepstatin A (0.2 mM), EDTA $(2 \mathrm{mM})$ and PmsF $(1 \mathrm{mM})$ were preincubated with the homogenates for $30 \mathrm{~min}$ prior to the addition of the azocasein substrate. All compounds were purchased by Sigma Aldrich (St. Louis, USA) and the solutions are given as final concentrations.

Haemonchus PBS soluble extracts were also checked for protease activity by gelatin gel electrophoresis as described by Ruiz et al. [22]. Briefly, gelatin was incorporated into $12 \%$ gel slabs at a final concentration of $0.1 \%$. Dilutions 1:3 of the homogenate in sampling buffer were applied into the gel and fractioned under non reducing conditions. Following electrophoresis at $100 \mathrm{~V}$ constant voltage for one hour at $4{ }^{\circ} \mathrm{C}$, the gels were washed in $2.5 \%$ Triton $\mathrm{X}-100$ for $30 \mathrm{~min}$ and rinsed extensively in $\mathrm{H}_{2} \mathrm{O}$ to remove the SDS. The effect of $\mathrm{pH}$ on the protease activity in the gels was determined using the same buffers as for the colorimetric assays. Incubations at $\mathrm{pH} 4,5$ and 6 were preceded by a preincubation at $37{ }^{\circ} \mathrm{C}$ for 30 min with 2 mM DTT. The zones of proteolysis were visualized by Coomassie blue staining after an incubation period of $16 \mathrm{~h}$ at $37^{\circ} \mathrm{C}$. For inhibitor sensitivity analysis, after electrophoresis, the gels were sliced, washed in $2.5 \%$ Triton X-100 and water and gel slices were incubated for $16 \mathrm{~h}$ with buffer containing the inhibitors E64 $(0.2 \mathrm{mM})$, Pepstatin A (0.2 nM), EDTA (2 mM) and PmsF (1 mM).

\subsection{Chromatography on Thiol-Sepharose}

After buffer exchange to Tris- $\mathrm{NaCl}$ buffer $\mathrm{pH} 7.4(10 \mathrm{mM}$ Tris, $0.5 \mathrm{M} \mathrm{NaCl})$ on a HiTrap-Desalting column (Amersham Pharmacia Biotech, Upsala, Sweden) at $5 \mathrm{~mL} /$ min, the Haemonchus PBS soluble protein extracts were applied to a Thiol-Sepharose column (Amersham Pharmacia Biotech, Upsala, Sweden) as described by Knox et al. [14]. Bound material was eluted by washing 
with the same buffer containing $25 \mathrm{mM}$ L-cysteine (Merck, Darmstadt, Germany). The peak fractions were pooled and the L-cysteine was removed by passage at $5 \mathrm{~mL} /$ min through the desalting column. The proteins present in these eluates are referred to as PBS soluble Thiol Sepharose binding proteins (PBS-TSBP).

\subsection{Peptide and protease composition of Haemonchus PBS-TSBP}

The activity and characterization of the proteases present in the eluates were demonstrated by colorimetric assays similar to those described in Section 2.2 using an antigen concentration of $140 \mu \mathrm{g} / \mathrm{mL}$. The general protein profile of these eluates was determined by SDS-PAGE (12\%) under non reducing conditions and compared to the protein fractionation observed in PBS soluble protein extracts.

\subsection{Animals and the immunization trial}

Twelve male goats from Gran Canaria (Spain) were reared from birth in covered pens in conditions designed to exclude helminth infections. They were fed with commercial pelleted rations for goats and water and mineralized salt were available "ad libitum". When the animals were six months old they were randomly allocated into three groups. No evidence of nematode infection was observed until that date. Group A $(n=5)$ was immunized on five consecutive weeks by intramuscular injections of 50,75, 100, 100 and $300 \mu \mathrm{g}$ of the cysteine protease enriched fractions. Freund complete adjuvant was used for the first immunization and Freund incomplete adjuvant for the rest. The animals from group B $(n=5)$ were subjected to the same protocol of inoculation but using buffer instead of the antigen. Groups A and B were challenged by intra-ruminal injection of 10000 $H$. contortus infective larvae on week 7 . Goats from group C $(n=2)$ were uninfected and unimmunized animals and served as controls. The presence of specific antibod- ies (IgG) against the immunogens was confirmed by indirect ELISA [19] using an antigen concentration of $1 \mu \mathrm{g} / \mathrm{mL}$ and dilutions of 1:200 and 1:4000 for the serum samples and conjugate (anti-goat IgG-peroxidase; Sigma Aldrich, St. Louis, USA), respectively.

Faecal egg counts were performed by the McMaster technique [29] two days a week from day 21 after challenge until the end of the experiment (week 15). At necropsy, the abomasa were removed, opened and washed, and the total number of worms were counted following standard procedures [16].

\subsection{Statistical methods}

Statistical analyses were performed by the $t$-Test and One Way ANOVA. Differences were considered significant for $P<$ 0.05. All data (eggs per gram of faeces, worm burden and IgG values) were uniformly distributed according to the Kolmogorov-Smirnov's Normality Test and were expressed as the mean \pm SEM (Standard Error of the Mean).

\section{RESULTS}

\subsection{Proteolytic activity of Haemonchus PBS soluble protein extracts}

The proteases present in the homogenates of $H$. contortus adult worms hydrolyzed azocasein over the $\mathrm{pH}$ range 4 to 8 with an optimum of $\mathrm{pH} 5$ (Fig. 1). The protease inhibitor E64 reduced the enzymatic activity by $50.5 \%$ at $\mathrm{pH} 5$ while no inhibitory effect was observed with EDTA, PmsF nor Pepstatin A.

Gelatin gels revealed one major fraction with proteolytic activity with an apparent molecular weight of approximately $35 \mathrm{kDa}$ (Fig. 2). This protease activity was only observed at $\mathrm{pH} 5$ and was completely inhibited by E64. EDTA, PmsF and Pepstatin A had no effect. 


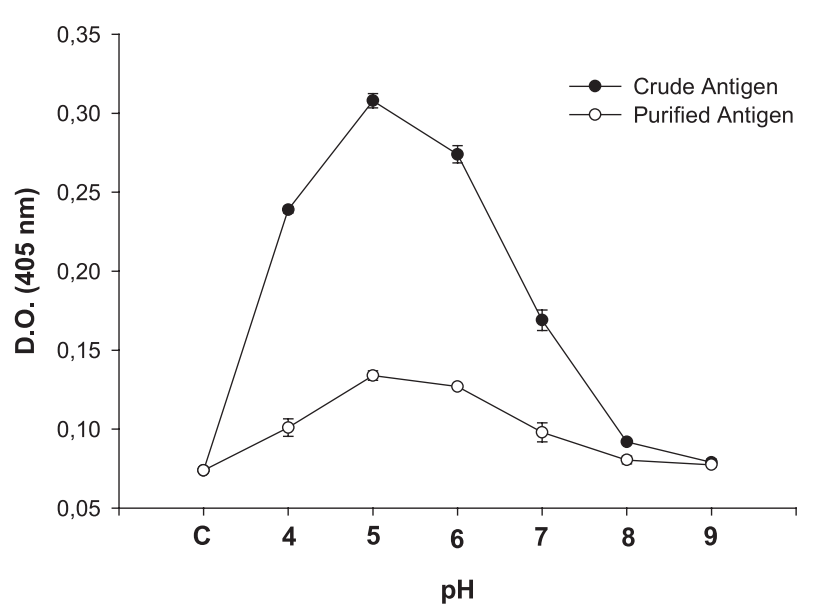

Figure 1. Proteolytic activity of PBS soluble protein extracts of adult Haemonchus contortus (Crude Antigen) and PBS-TSBP (Purified Antigen) determined by spectrophotometry using azocasein as the substrate. The optimum $\mathrm{pH}$ was determined using $0.1 \mathrm{M}$ Phosphate $(\mathrm{pH} 4,5$ and 6$)$ or $0.1 \mathrm{M}$ Tris- $\mathrm{HCl}(\mathrm{pH} 7,8$ and 9) as incubation buffers. The corresponding buffer at $\mathrm{pH} 5$ was used as the control. Values are expressed as the mean \pm SEM of duplicated assays.

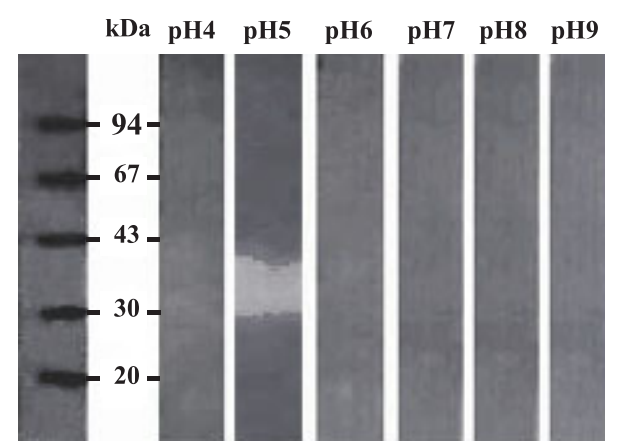

Figure 2. Gelatin gel electrophoresis of Haemonchus PBS soluble protein extracts. The optimum $\mathrm{pH}$ was determined using $0.1 \mathrm{M}$ Phosphate $(\mathrm{pH} 4$, 5 and 6) and $0.1 \mathrm{M}$ Tris- $\mathrm{HCl}(\mathrm{pH} \mathrm{7,8}$ and 9) as incubation buffers. Zones of proteolysis were visualized by Coomassie blue staining after an incubation period of $16 \mathrm{~h}$ at $37^{\circ} \mathrm{C}$.

\subsection{Peptide and protease composition of Haemonchus PBS-TSBP}

Under non reducing conditions, Haemonchus PBS-TSBP comprised a prominent band at approximately $60 \mathrm{kDa}$ and a faintly staining material with a slightly higher molecular weight (62-64 kDa) (Fig. 3). Two additional proteins visualized around $35 \mathrm{kDa}$ (see arrow in Fig. 3) might presumably correspond to the proteases of similar molecular weight detected by gelatin gel electrophoresis (Fig. 2).

The protease activity of Haemonchus PBS-TSBP fractions (purified antigen) was present over the $\mathrm{pH}$ range 4 to 8 with an optimum of $\mathrm{pH} 5$ and a similar profile to that observed for the Haemonchus PBS soluble protein extracts (crude antigen) (Fig. 1). The enzymatic activity was reduced by $42.5 \%$ with E64 at pH 5 and unaffected by EDTA, PmsF or Pepstatin A.

\subsection{Antibody response of immunized goats}

Specific antibodies (IgG) against the enriched cysteine protease fractions used as immunogens were first observed in group $\mathrm{A}$ three weeks after the first immunization, reached peak values at week 7 and remained significantly high until the end of the experiment in relation to control groups $\mathrm{B}$ and $\mathrm{C}$ $(P<0.001)$ (Fig. 4). 
kDa

MwM Hc-CA Hc-PA

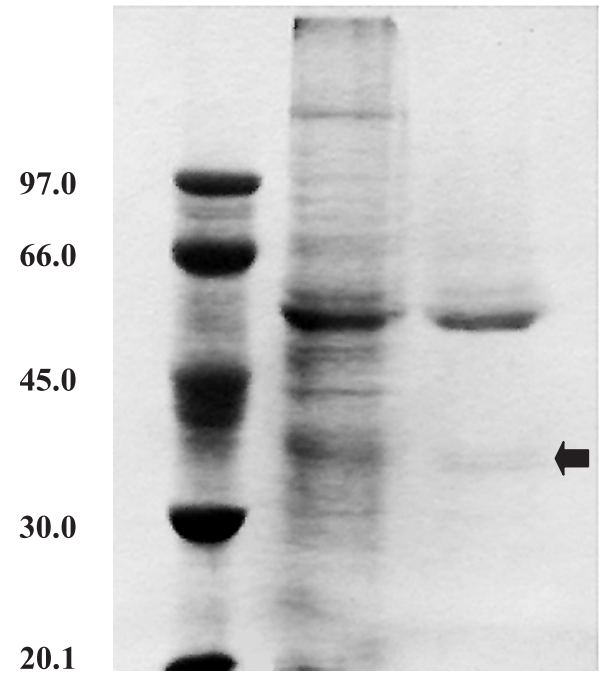

Figure 3. SDS-PAGE (12\%) fractionation in non reducing conditions of Haemonchus PBS soluble protein extracts (Hc-CA) and PBSTSBP (Hc-PA) visualized by Comassie blue staining. The first lane (MwM) shows the molecular weight marker and the arrow the cysteine protease components of the PBS-TSBP antigen.

\subsection{Egg counts and worm recovery}

Positive egg counts were observed from week 5 post-challenge. From this week onwards, the number of eggs per gram of faeces (EPG) was lower in the immunized goats (from 0 to $150 \mathrm{EPG}$ ) than in the nonimmunized animals (from 150 to $850 \mathrm{EPG}$ ). Differences were significant $(P<0.05)$ from week 6 post-challenge until the end of the experiment (Fig. 5). Accordingly, the EPG averaged over the whole experiment for unvaccinated goats $(550 \pm 13.5)$ was significantly $(P<0.001)$ greater than those of vaccinated goats $(61 \pm 2.9)$.

The number of adult worms recovered from the abomasa at necropsy was statistically different between the groups $(P<$ $0.05)$, with mean values of $247.5 \pm 43.8$ and $762.5 \pm 78.3$ worms per animal in the immunized and non immunized goats, respectively.

\section{DISCUSSION}

The present study demonstrates that a cysteine protease enriched fraction of adult

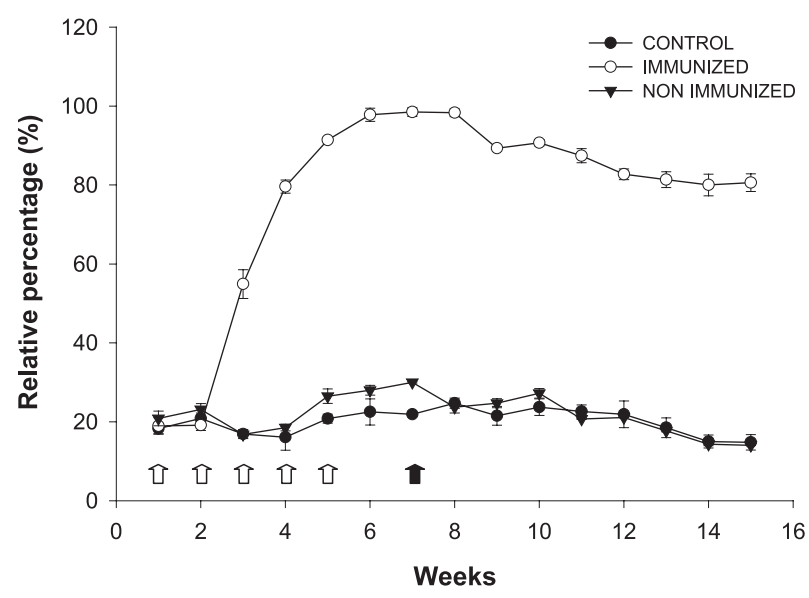

Figure 4. IgG response (mean \pm SEM) in goats immunized with Haemonchus PBS-TSBP and challenged with $10000 \mathrm{H}$. contortus L3 (Immunized, group A), injected only with adjuvant and challenged (Non-immunized, group B) and non-immunized and non-infected (Control, group C). The OD of each serum sample was expressed as a percentage (\% relative) of the OD value observed in a positive pool. The time of each vaccination (open arrows) and the time of challenge (closed arrow) are indicated. 


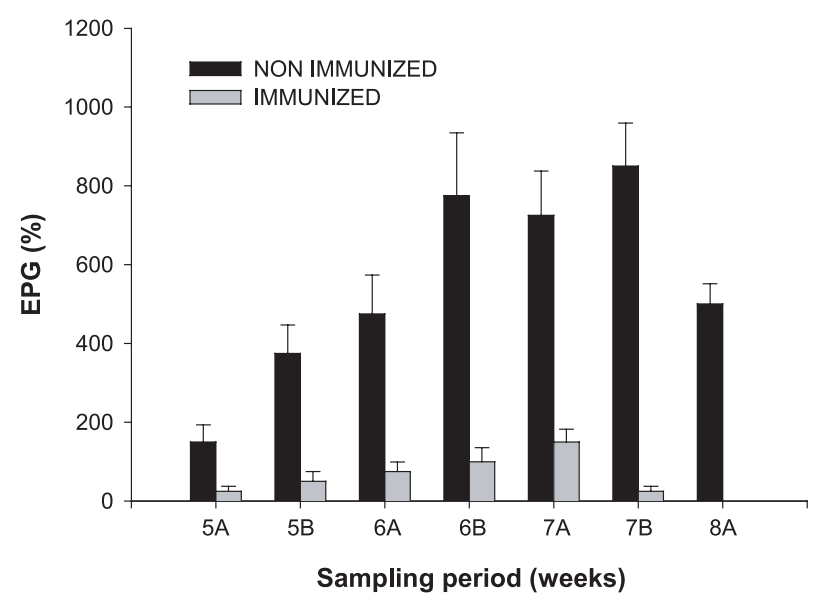

Figure 5. Eggs per gram of faeces (EPG) expressed as mean \pm SEM in goats immunized with Haemonchus PBS-TSBP and challenged with $10000 \mathrm{H}$. contortus L3 (Immunized, group A) and goats injected only with adjuvant and challenged (Non-immunized, group B). Samples were counted twice a week and are labelled A or B.

H. contortus has an immunoprotective effect for goats. According to molecular weight, optimum $\mathrm{pH}$ and the inhibition by E64, the proteases identified here seem to be cysteine proteases similar to those described previously in different ovine strains of the parasite $[12,13]$. A cysteine protease of $35 \mathrm{kDa}$ was first reported by Cox et al. [5] as a major component of protein extracts isolated from ovine $H$. contortus adult worms.

The levels of immunoprotection observed in this study approached those obtained in goats using gut protein from $H$. contortus [10] and those achieved in sheep using excretory-secretory products [23], antigens purified from larvae [9] or different adult membrane antigens $[7,17,26]$. The percentages of egg and worm reduction were also comparable to those attained by Knox et al. [14] in sheep using enriched cysteine proteases purified from Triton X-100 soluble membrane-bound protein extracts from adult worms (S3). By contrast, these authors only achieved a marginal, not significant reduction in egg output when using as immunogen a combination of PBS soluble (S1) and Tween 20 soluble (S2) membraneassociated protein extracts purified by a similar methodology. The disparity between the immunoprotective effect of PBS soluble extracts against haemonchosis reported by Knox et al. [14] and that obtained in the present investigation may be due to the peculiarities of each immunization trial. Actually, although the total amount of antigen was approximately the same in both studies, the number of immunizations, the doses of antigen used in each immunization and the period between immunizations were different. Besides, Knox et al. [14] used the Freund complete adjuvant for all three immunizations with $\mathrm{S} 1 / \mathrm{S} 2$ parasite extracts. Discrepancies obtained between the present experiment and this previous one may also account for differences in the immunogenicity of the PBS soluble extracts employed in each study. Proteases purified by Knox et al. [14] from S1/S2 extracts had molecular weights between 50 and $55 \mathrm{kDa}$, which differs from the $35 \mathrm{kDa}$ cysteine proteases reported here. A Haemonchus protease with similar molecular weight was identified by Cox et al. [6] in a fibrinogenase complex marginally protective for sheep [2]. Supporting geographic differences between cysteine proteases, in a UK strain of $H$. contortus 
Skuce et al. [24] failed to amplify any gene of the AC-family or gcp7 identified in USA strains of the parasite $[19,20]$. Instead, a panel of six protease homologues (designated $h m c p 1-6$ ) was amplified. Host factors should also be taken into consideration when the immunoprophylactic value of a particular antigen is investigated. Therefore, sheep (Knox et al. [14]) and goats (the present study) do not necessarily have identical responses to immunization with PBS soluble extracts and have different susceptibilities to nematode parasite infections [8, 18]. Actually, compared to published data from sheep $[2,14]$ we found positive egg counts 1-2 weeks latter and relative low EPG.

Colorimetric assays indicate that the passage of PBS soluble protein extracts through Thiol Sepharose resulted in approximately a 10-fold enrichment of protease activity. The similarities in the $\mathrm{pH}$ influence (Fig. 1) and the inhibition by E64 between the crude antigen and the purified antigen (PBSTSBP) used in the immunizations suggested that the immunogen included cysteine proteases similar to those characterized for the Haemonchus PBS soluble protein extracts. However, as judged by the peptide profile of the purified antigen (Fig. 3) the IgG production and consequently the protection observed may not only be attributable to the cysteine protease components of PBS-TSBP. Actually, the $60 \mathrm{kDa}$ band probably corresponds to glutamate dehydrogenase, which is also the major protein component in TSBP from detergent extracts of Haemonchus. This band was strongly recognized by antisera from sheep demonstrably protected following immunization with these TSBP detergent extracts [25].

The PBS-TSBP antigens would be expected to contain cysteine proteases released from the intestine of the parasite as E/S products [27] and hence could interact with the host immune system. In the present study we found high levels of anti-PBS-TSBP antibodies from the third immunization onwards, but no significant increase was detected after the challenge with $H$. contortus infective larvae. Probably, the IgG production stimulated by the parasite infection was imperceptible when compared to IgG induced by the immunizations. Besides, apart from the potential action of the antibodies on the gut surface proteins, the protection could also depend on the local or cell-mediated immunity, which has not been tested here. The intrinsic mechanism of immunoprotection developed by PBS-TSBP can not be inferred from the present study. Further investigations should be addressed to elucidate the particularities of the immune response of goats vaccinated with these antigens including additional fractionation experiments and the evaluation of different types of adjuvants.

\section{ACKNOWLEDGEMENTS}

This research has been supported by the Spanish Ministry of Science and Technology, and by the FEDER Funds (Project AGL2002-03528).

\section{REFERENCES}

[1] Bakker N., Vervelde L., Kanobana K., Knox D.P., Cornelissen A.W., Vries E., Yatsuda A.P., Vaccination against the nematode Haemonchus contortus with a thiol-binding fraction from the excretory/secretory products (ES), Vaccine 22 (2004) 618-628.

[2] Boisvenue R.J., Seiff M.I., Tonkinson L.V., Cox G.N., Hageman R., Fibrinogen-degrading proteins from Haemonchus contortus used to vaccinate sheep, Am. J. Vet. Res. 53 (1992) 1263-1265.

[3] Bradford M.M., A rapid and sensitive method for the quantification of microgram quantities of protein utilizing the principle of protein dye-binding, Anal. Biochem. 72 (1976) 248254.

[4] Coles G.C., Cattle nematodes resistant to anthelmintics: why so few cases? Vet. Res. 33 (2002) 481-489.

[5] Cox G.N., Pratt D., Hageman R., Boisvenue R.J., Molecular cloning and primary sequence of a cysteine protease expressed by Haemonchus contortus adult worms, Mol. Biochem. Parasitol. 41 (1990) 25-34.

[6] Cox G.N., Milhaussenm M., Hageman R. Anticoagulant and anthelmintic proteins and methods for the production of the same, European Patent Application (1991) 0434909 A2. 
[7] Domínguez-Torano I.A., Cuquerella M., Gómez-Muñoz M.T., Méndez S., FernándezPérez F.J., Alunda J.M., Vaccination of Manchego lambs against Haemonchus contortus with a somatic fraction (p26/23) of adult parasites, Parasite Immunol. 22 (2000) 131-138.

[8] Hoste H., Chartier C., Goat resistance to trichostrongyle infections of the gastrointestinal tract, Point Vét. 29 (1998) 161-166 (in French).

[9] Jacobs D.P., Wiltshire C., Ashman K., Meeusen E.N.T., Vaccination against the gastrointestinal nematode, Haemonchus contortus, using a purified larval surface antigen, Vaccine 17 (1999) 362-368.

[10] Jasmer D.P., McGuire T.C., Protective immunity to a blood-feeding nematode (Haemonchus contortus) induced by parasite gut antigens, Infect. Immun. 59 (1991) 4412-4417.

[11] Kaplan R.M., Anthelmintic resistance in nematodes of horses, Vet. Res. 33 (2002) 491507.

[12] Karanu F.N., Rurangirwa F.R., Mcguire T.C., Jasmer D.P., Haemonchus contortus: identification of proteases with diverse characteristics in adult worm excretory-secretory products, Exp. Parasitol. 77 (1993) 362-371.

[13] Knox D.P., Redmond D.L., Jones D.G., Characterization of proteases in extracts of adult Haemonchus contortus, the ovine abomasal nematode, Parasitology 106 (1993) 395-404.

[14] Knox D.P., Smith S.K., Smith W.D., Immunization with affinity purified protein extract from the adult parasite protects lambs against infection with Haemonchus contortus, Parasite Immunol. 21 (1999) 201-210.

[15] Lumaret J.P., Errouissi F., Use of anthelmintics in herbivores and evaluation of risks for the non targets fauna of pastures, Vet. Res. 33 (2002) 547-562.

[16] Manual of Veterinary Parasitological Techniques, 3rd ed., London, MAFF, 1986.

[17] Munn E.A., Smith T.S., Smith H., James F.M., Smith F.C., Vaccination against Haemonchus contortus with denatured forms of the protective antigen H1 1, Parasite Immunol. 19 (1997) 243-248.

[18] Pomroy W.E., Lambert M.G., Betteridge L., Comparison of faecal strongylate egg counts of goats and sheep on the same pasture, N. Z. Vet. J. 34 (1985) 36-37.

[19] Pratt D., Armes L.G., Hageman R., Reynolds V., Boisvenue R.J., Cox G.N., Cloning and sequence comparisons of four distinct cysteine proteases expressed by Haemonchus contortus adult worms, Mol. Biochem. Parasitol. 51 (1992) 209-218.

[20] Rehman A., Jasmer D.P., A tissue specific approach for analysis of membrane and secreted protein antigens from Haemonchus contortus gut and its application to diverse nematode species, Mol. Biochem. Parasitol. 97 (1998) 55-68.

[21] Rhoads M.L., Fetterer R.H., Developmentally regulated secretion of cathepsin L-like cysteine proteases by Haemonchus contortus, J. Parasitol. 81 (1995) 505-512.

[22] Ruiz A., Molina J.M., González J., Martínez F.J., Gutierrez P.N., Martínez A., Humoral response $(\mathrm{IgG})$ in goats experimentally infected with Fasciola hepatica against cysteine proteases of adult fluke, Vet. Res. 34 (2003) 435443.

[23] Schallig H.D., Van Leeuwen M.A., Cornelissen A.W., Protective immunity induced by vaccination with two Haemonchus contortus excretory secretory proteins in sheep, Parasite Immunol. 19 (1997) 447-453.

[24] Skuce P.J., Redmond D.L., Liddell S., Stewart E.M., Newlands G.F., Smith W.D., Knox D.P., Molecular cloning and characterization of gut-derived cysteine proteases associated with a host protective extract from Haemonchus contortus, Parasitology 119 (1999) 405412 .

[25] Skuce P.J., Stewart E.M., Smith W.D., Knox D.P., Cloning and characterization of glutamate dehydrogenase (GDH) from the gut of Haemonchus contortus, Parasitology 118 (1999) 297-304.

[26] Smith S.K., Pettit D., Newlands G.F., Redmond D.L., Skuce P.J., Knox D.P., Smith W.D., Further immunization and biochemical studies with a protective antigen complex from the microvillar membrane of the intestine of Haemonchus contortus, Parasite Immunol. 21 (1999) 187-199.

[27] Shompole S., Jasmer D.P., Cathepsin B-like cysteine proteases confer intestinal cysteine protease activity in Haemonchus contortus, $\mathrm{J}$. Biol. Chem. 276 (2001) 2928-2934.

[28] Silvestre A., Leignel V., Berrag B., Gasnier N., Humbert J.F., Chartier C., Cabaret J., Sheep and goat nematode resistance to anthelmintics: pro and cons among breeding management factors, Vet. Res. 33 (2002) 465-480.

[29] Thienpont D., Rochette F., Van Parijs O.F.J., Diagnosing Helminthiasis by Coprological Examination, Janssen Research Foundation, Beerse, 1979, p. 187.

[30] Van Wyk J.A., Malan F.S., Randles J.L., How long before resistance makes it impossible to control some field strains of Haemonchus contortus in South Africa with any of the modern anthelmintics? Vet. Parasitol. 70 (1997) 111-122.

[31] Waller P.J., The development of anthelmintic resistance in ruminant livestock, Acta Trop. 56 (1994) 233-243. 